International Journal of Agriculture, Environment and Bioresearch

Vol. 5, No. 03; 2020

ISSN: $2456-8643$

\title{
MICRO SATELLITE MARKERS SCREENING FOR COFFEE BERRY DISEASE (COLLETOTRICHUM KAHAWAE) RESISTANCE IN PROGENIES OF VARIETY KP423 AND ETHIOPIAN COFFEE ARABICA ACCESSIONS
}

\author{
MTENGA, Damian $\mathrm{J}^{1}$., KUSOLWA, Paul M., ${ }^{2}$ REUBEN, Shazia. O.W.M ${ }^{2}$ and KILAMBO, Deusdedit L. ${ }^{1}$ \\ ${ }^{1}$ Tanzania Coffee Research Institute P.O.Box 3004 Moshi, Tanzania \\ ${ }^{2}$ Sokoine University of Agriculture P.O Agriculture P.O. Box 3005 Morogoro, Tanzania
}

https://doi.org/10.35410/IJAEB.2020.5501

\begin{abstract}
Coffee berry disease (CBD), caused by Colletotrichum kahawae, is a major constraint for Arabica coffee cultivation in Africa. Several previous studies have revealed molecular markers associated with its resistance. CBD is a disease that attacks berries at different developmental stages. The current study was aimed at using of these markers to screen for resistance to the disease on genotypes and progenies developed from the Tanzanian commercial variety and Ethiopian accessions at seedling stage. Eleven Ethiopian genotypes were crossed to a variety KP423. F1 progenies and their parental genotypes were used in the study. Physiological screening was applied on the hypocotyls of parental genotypes and F1 progenies using the procedure developed by Van der Vossen in 1976. Marker screening was applied on the DNA extracted from their young tender leaves using gene specific markers Sat 235 and Sat 207. The presence of the coffee berry disease resistance genes was revealed in the studied coffee genotypes amplified by SSR marker Sat 235 and Sat 207. This was confirmed by production of bands similar to the progenitors of CBD resistance. These findings implied that marker screening can be used in coffee berry disease resistant genotypes selection at early stages of growth hence reducing the time of selection cycle.
\end{abstract}

Keywords: Microsatellite markers, coffee berry disease, marker screening.

\section{INTRODUCTION}

Coffee production in Tanzania is constrained by several factors. However, the major challenge is the management of diseases and insect pests. In Arabica coffee, coffee berry disease (CBD) and coffee leaf rust (CLR) diseases are the major challenges while in Robusta the big challenge is combating coffee wilt disease (CWD) (TCB, 2012). Epidemics of CBD can destroy 70-80\% of the developing berries on susceptible arabica cultivars during prolonged wet and cool weather conditions (Van der Vossen and Walyaro, 2009). Preventive control measures by frequent fungicide sprays accounts for 30-40\% of total production costs. Annual economic damage to arabica coffee production in Africa, due to crop loss by CBD and the cost of chemical control, is estimated at US\$ 300-500 million (Van der Vossen and Walyaro, 2009). Tanzania maintains about 196 accessions of Ethiopian coffee origin collected and distributed by the FAO coffee collection mission (FAO, 1968). Ethiopian arabica coffee cultivars are likely to be extremely 
valuable to other countries in Africa, where CBD prevents the cultivation of arabica coffee, particularly by the poor farmers. Traits of interest in perennial crops such as disease resistance can be observed and screened only at late stages of development and require assessment over a number of years at different locations. The objective of this study was to screen progenies and parental genotypes of Ethiopian accessions and Tanzanian commercial variety KP423 for CBD resistance using microsatellite markers

\section{MATERIALS AND METHODS}

\section{Plant materials}

Eleven coffee genotypes (Table 1) were crossed to a susceptible commercial variety KP423, and the parents and their F1 progenies were screened phenotypically for coffee berry disease resistance using hypocotyl test (Van der Vossen et al., 1976).

Table 1: List of coffee genotypes used for coffee berry disease resistance screening

\begin{tabular}{|lll|}
\hline Genotypes & Description & Code \\
\hline F45/64/2049 x KP423 & F1 hybrid & 101 \\
F90/64/4660 x KP423 & F1 hybrid & 102 \\
Rume SudanVC298 x KP423 & F1 hybrid & 103 \\
F45/64/2061 x KP423 & F1 hybrid & 104 \\
F24/64/902 x KP423 & F1 hybrid & 105 \\
F24/64/886 x KP423 & F1 hybrid & 106 \\
PRO127 x KP423 & F1 hybrid & 107 \\
F89/64/4650 x KP423 & F1 hybrid & 108 \\
KP423 & Commercial & 109 \\
F24/64/886 & Ethiopian & 110 \\
PRO127 & Resistance donor & 111 \\
F89/64/4650 & Resistance donor & 112 \\
Rume SudanVC298 & Resistance donor & 113 \\
PNI088 & Resistance donor & 114 \\
Sarchimor & Resistance donor & 115
\end{tabular}


International Journal of Agriculture, Environment and Bioresearch

Vol. 5, No. 03; 2020

ISSN: 2456-8643

VCE1593

Resistance donor

116

F90/64/4660

Ethiopian

F45/64/2049

Ethiopian

F45/64/2061

Ethiopian

F24/64/902

Ethiopian

120

\section{Microsatellite markers used}

Two gene specific SSR markers for coffee berry disease (CBD) resistance - Sat235 and Sat207 identified from literature (Gichuru et al., 2008) and which were sourced from Eurofins MWG Operon Ebersberg, Germany with primer sequences described in Table 2 were used.

Table 2: Gene specific SSR markers used in coffee berry disease resistance screening

\begin{tabular}{|c|c|c|c|c|}
\hline & $\begin{array}{l}\text { Marker } \\
\text { name }\end{array}$ & & Primer $\left(5^{\prime}-3^{\prime}\right)$ Sequence & Reference \\
\hline \multirow[t]{2}{*}{1} & Sat207 & $\mathrm{F}$ & GAAGCCGTTTCAAGCC & $\begin{array}{l}\text { Gichuru et al., } \\
2008\end{array}$ \\
\hline & & $\mathrm{R}$ & CAATCTC TTTCCGATGCTCT & \\
\hline \multirow[t]{2}{*}{2} & Sat235 & $\mathrm{F}$ & TCGTTCTGTCATTAAATCGTCAA & $\begin{array}{l}\text { Gichuru et al., } \\
2008\end{array}$ \\
\hline & & $\mathrm{R}$ & $\begin{array}{l}\text { GCAAATCATGAAAATAGTTGGT } \\
\text { G }\end{array}$ & \\
\hline
\end{tabular}

\section{Screening for CBD resistance}

\section{Phenotypic Screening}

Ripe coffee berries were harvested from the selected eleven parental genotypes while at the same time mature and ripe F1 crosses were harvested and processed separately maintaining the identity of the parental genotypes and hybrids. Two hundred seeds of each coffee genotype and F1 hybrid were sown, with the parchment removed in moist sterilized sand in plastic boxes with transparent lids. The boxes were then kept at room temperatures $\left(20-24^{\circ} \mathrm{C}\right)$. The seedlings were inoculated when their hypocotyl stems were $3-5 \mathrm{~cm}$ long at the $5-6^{\text {th }}$ weeks after sowing. The experiment was arranged in the laboratory in a completely randomized design with four replications. Each replicate was represented by 50 hypocotyl seedlings; a row of 10 seedlings of the susceptible KP423 and resistant PNI088 control pre-germinated alongside the F1 and 
Vol. 5, No. 03; 2020

ISSN: $2456-8643$

parental genotypes in a plastic box. The seedlings were inoculated the same day with conidia suspensions from 10 days old cultures standardized to $2 \times 10^{6}$ conidia/ml following the procedure of Van der Vossen et al. (1976). Just before inoculation the lids were removed from the plastic boxes and the seedlings were sprayed with the standard CBD inoculum $\left(2 \times 10^{6}\right.$ spores/ml $)$ by a small hand atomizer held at $10 \mathrm{~cm}$ from the hypocotyls and the boxes were immediately closed again. The inoculation was repeated after 48 hours. Temperature of $22-24^{\circ} \mathrm{C}$ was maintained for the first four days, while relative humidity in the boxes was maintained at $100 \%$. Incubation period at lower constant temperature $\left(19-20^{\circ} \mathrm{C}\right)$ followed with the lids removed to allow for normal humidity. Incubation period of two weeks was required for a full expression of disease reaction. Four weeks after inoculation, coffee seedlings were individually scored for CBD disease symptoms developed on the hypocotyl stem using a scale of 0-4 (Van der Graaff, 1978)., where $(0=$ absence of symptoms, $1=$ one or two small brownish chlorotic lesions, $2=$ coalescence brownish lesions, 3 = abundant black lesions, 4 = dead hypocotyls). Mean score data were subjected to analysis of variance using GenStat Version 12.1 statistic software by VSN International Ltd and mean separation was done as per Fisher (1958).

\section{Markers screening}

Young coffee leaves were picked from the growing tips of ten seedlings of the eleven genotypes and their $F_{1}$ hybrids which were found resistant to CBD in the phenotypic CBD resistance screening for DNA extraction. Leaf samples from the susceptible variety KP423 were picked from the seedlings of the same age but which were not subjected to phenotypic CBD resistance screening. All samples were lyophilized 72 hours before DNA extraction.

\section{DNA extraction}

The lyophilized leaves were stored at $-21^{\circ} \mathrm{C}$ before DNA extraction. Genomic DNA was extracted from the lyophilized leaves following the CTAB method (Diniz et al., 2005). About $500 \mathrm{mg}$ of the lyophilized leaves were ground in eppendorf tubes using mortar and pestle. One $\mathrm{ml}$ each of lysis and extraction buffers was added to the powder in the eppendorf tube. The ground tissue was distributed in two $1.5 \mathrm{ml}$ tubes and incubated at $65^{\circ} \mathrm{C}$ in a water bath for $25 \mathrm{~min}$ with regular shaking. After incubation, $1 \mathrm{ml}$ of chloroform/isoamyl-alcohol mixture in the ratio of 24:1 was added to each tube, then mixed gently by shaking and centrifuged at $13000 \mathrm{rpm}$ for $15 \mathrm{~min}$ in a micro-centrifuge. The supernatants were pipetted out into new $1.5 \mathrm{ml}$ tubes. $20 \mu \mathrm{l}$ of RNase were added to the supernatants and incubated at $37^{\circ} \mathrm{C}$ in a water-bath for $30 \mathrm{~min}$. An equal volume of isopropyl alcohol was added into each tube and mixed gently by inverting the tubes several times to precipitate DNA. The suspended DNA was centrifuged at $13000 \mathrm{rpm}$ for 5 min to obtain a DNA pellet and the supernatant carefully removed. The DNA pellets were then washed with $200 \mu \mathrm{l}$ of $70 \%$ ethanol and centrifuged at $13000 \mathrm{rpm}$ for $3 \mathrm{~min}$. The ethanol was drained by decanting and the pellets dried in a vacuum centrifuge for $20 \mathrm{~min}$. The pellets were dissolved in $60 \mu \mathrm{l}$ of Tris-EDTA (TE) buffer and stored at $4^{\circ} \mathrm{C}$. DNA quality and quantity were quantified on $1 \%$ agarose gel in $0.5 x$ TAE (Tris-Acetate-EDTA) buffer, stained with ethidium bromide and visualized under UV light.

\section{Coffee genomic DNA amplification}


Extracted coffee genomic DNA was amplified on GeneAmp PCR System 9700 thermocycler Applied BioSystems USA using two microsatellite primers designed by Eurofins MWG Operon LLC USA (Table 2). Touchdown PCR procedure (Poncet et al., 2004) was followed. The PCR reactions for the SSR markers were made in $20 \mu \mathrm{L}$ containing $2.0 \mu \mathrm{L}$ of $10 \mathrm{x}$ buffer, $150 \mathrm{mM} / \mathrm{L}$ of dNTP, $0.1 \mathrm{mM} / \mathrm{L}$ of each primer, $25 \mathrm{ng}$ of DNA, $1 \mathrm{mM} / \mathrm{L} \mathrm{MgCl}_{2}, 1$ Unit Taq DNA polymerase and the remaining volume was completed with PCR water. The reaction consisted of initial denaturation at $94^{\circ} \mathrm{C} / 10 \mathrm{~min}$, followed by 10 cycles of denaturation at $94^{\circ} \mathrm{C} / 30 \mathrm{~s}$, annealing at $50^{\circ} \mathrm{C} / 30 \mathrm{~s}$, and extension at $72^{\circ} \mathrm{C} / 1 \mathrm{~min}$. followed by a final extension at $72^{\circ} \mathrm{C} / 7 \mathrm{~min}$. All amplified products were confirmed by $2.0 \%$ (wt/vol) 1.e (low electroendosmosis) agarose gel electrophoresis in $1 \times$ TAE and EDTA) buffer at $120 \mathrm{~V} / 115 \mathrm{~mA} / 15 \mathrm{~W}$ for $2.30 \mathrm{hrs}$ with ethidium bromide post-staining $(0.5 \mu \mathrm{l} / \mathrm{ml})$ for $30 \mathrm{~min}$, followed by $10 \mathrm{~min}$ of destaining in $1 \times$ TAE buffer and visualized on UV. The reproducibility of the amplification products was checked twice for each primer.

\section{RESULTS AND DISCUSSION}

\section{Phenotypic screening}

Coffee berry disease resistance phenotypic screening mean data on parental genotypes are presented in Table 3. There is significant $(\mathrm{p}<0.05)$ difference among the parental genotypes. Four groups were deduced from the mean separation. The variety KP423 had a mean score of 3.6 being the highest infection of CBD in the parental genotypes. Ethiopian coffee genotype F24/64/T2061 had a mean score of 1.3 significantly $(\mathrm{p}<0.05)$ differing from the rest of the parental coffee genotypes. The performance of the F1 hybrids of the cross between the parental genotypes and a CBD susceptible variety KP423 (Table 4) revealed significant $(\mathrm{p}<0.05)$ difference on coffee berry disease resistance. The commercial variety KP423 had the highest CBD mean score (3.7).

Table 3: Coffee parental genotypes Coffee berry disease resistance mean score on (0-4 scale)

\begin{tabular}{|ll|}
\hline Genotype & Mean \\
\hline SARHIMOR & $0.08 \mathrm{a}$ \\
VC298 & $0.08 \mathrm{a}$ \\
F90/64/T4660 & $0.10 \mathrm{a}$ \\
PNI088 & $0.18 \mathrm{a}$ \\
VCE1593 & $0.34 \mathrm{ab}$ \\
F45/64/T2049 & $0.38 \mathrm{ab}$ \\
F89/64/T4650 & $0.38 \mathrm{ab}$
\end{tabular}


Vol. 5, No. 03; 2020

ISSN: $2456-8643$

\begin{tabular}{|l|l|} 
PRO127 & $0.62 \mathrm{bc}$ \\
F24/64/902 & $0.91 \mathrm{~cd}$ \\
F24/64/T886 & $0.93 \mathrm{~cd}$ \\
F24/64/T2061 & $1.26 \mathrm{~d}$ \\
KP423 & $3.56 \mathrm{e}$ \\
\hline
\end{tabular}

Mean values on the same column having the same letter(s) are not significantly different at $\mathrm{p} \leq 0.05$ according to Fisher. Disease scale (0-4) where 0 most resistant and 4 very susceptible.

Table 4: Coffee F1 hybrids Coffee Berry Disease resistance mean score on (0-4 scale)

\begin{tabular}{|ll|}
\hline Genotype & Mean \\
\hline VC298 x KP423 & $0.11 \mathrm{a}$ \\
F90/64/T4660 x KP423 & $0.14 \mathrm{a}$ \\
VCE1593 x KP423 & $0.24 \mathrm{ab}$ \\
F89/64/T4650 x KP423 & $0.34 \mathrm{bc}$ \\
PNI 088 x KP423 & $0.41 \mathrm{~cd}$ \\
SARCHIMOR x KP423 & $0.42 \mathrm{~cd}$ \\
F45/64/T2049 x KP423 & $0.43 \mathrm{cde}$ \\
PRO127 x KP423 & $0.46 \mathrm{cde}$ \\
F24/64/T2061 x KP423 & $0.50 \mathrm{def}$ \\
F24/64/902 x KP423 & $0.56 \mathrm{ef}$ \\
F24/64/T886 x KP423 & $0.64 \mathrm{f}$ \\
KP423 & $3.68 \mathrm{~g}$ \\
\hline
\end{tabular}

Mean values on the same column having the same letter(s) are not significantly different at $\mathrm{p} \leq 0.05$ according to Fisher. Disease scale (0-4) where 0 most resistant and 4 very susceptible.

\section{Marker screening}

The results of amplification of the 20 genotypes including parents and F1 hybrids (Fig. 1) by the SSR marker Sat235 shows that the following coffee genotypes and hybrids were amplified F45/64/2049 x KP423 (101), F90/64/4660 x KP423 (102), F45/64/2061 x KP423 (104), F24/64/902 x KP423 (105), F24/64/886 x KP423 (106), PRO127 x KP423 (107), F89/64/4650 x 
KP423 (108), PRO127 (111), F89/64/4650 (112), VC298 (113), PNI088 (114) Sarchimor (115), VCE1593 (116), F90/64/4660 (117), F45/64/2049 (118), F45/64/2061 (119) and F24/64/902 (120). The coffee genotypes Rume Sudan VC298 x KP423 (103), KP423 (109) and F24/64/886 (110) were not clearly amplified. The Ethiopian F1coffee hybrids and parental genotypes that were amplified by SSR marker Sat207 (Fig. 2) included F45/64/2049 x KP423 (101), F90/64/4660 x KP423 (102), F45/64/2061 x KP423 (104), F24/64/902 x KP423 (105), F24/64/886 x KP423 (106), F89/64/4650 x KP423 (108), F90/64/4660 (117), F45/64/2049 (118), F45/64/2061 (119) and F24/64/902 (120) while Ethiopian parental genotype F24/64/886 (110) was not amplified (Fig. 2).

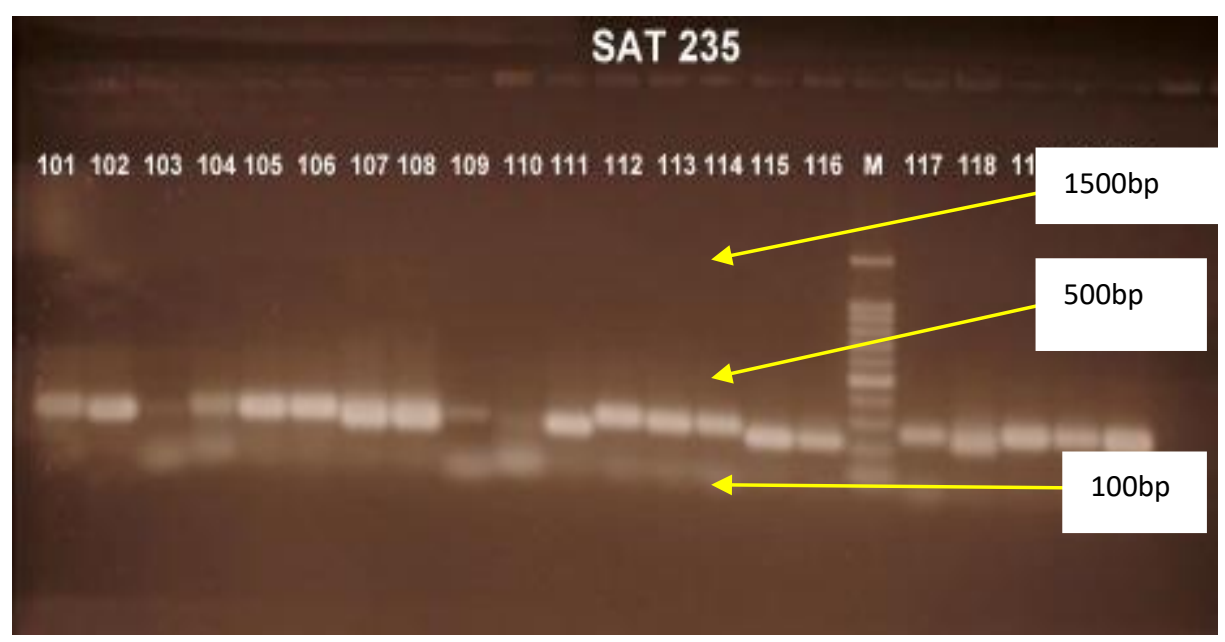

Figure 1: A 2\% gel photograph showing amplification of coffee parental genotypes, F1 hybrids and a commercial variety KP423 by SSR marker Sat 235 .

Lanes 101-120 represent coffee genotypes. Lane M represents a 100-bp ladder and lane C+ represent a control of a known amplification.

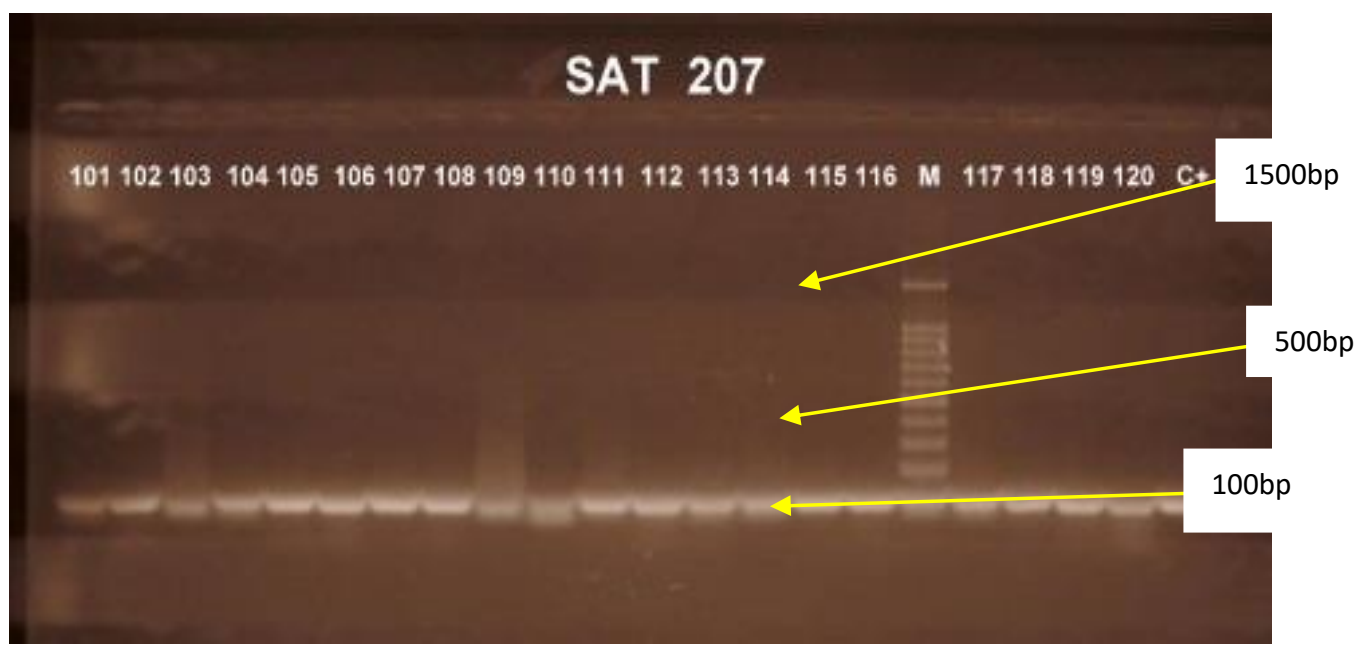


Figure 2: A 2\% gel photograph showing amplification of coffee parental genotypes, F1 hybrids and a commercial variety KP423 by SSR marker Sat 207.

Lanes 101-120 represent genotypes. Lane M represents a 100-bp ladder and lane C+ and Crepresents controls of a known amplification.

Phenotypic CBD screening revealed that all coffee parental genotypes and F1 hybrids were medium to highly resistant to CBD (Tables 3 and 4). One Ethiopian coffee parental genotype F24/64/T2061 (Table 3) scored a mean of 1.256 which indicates medium resistance to CBD. The commercial coffee variety KP423 clearly showed its susceptibility scoring a mean of 3.68 and 3.68 respectively (Table 3 and 4). Phenotypic hypocotyl screening for CBD resistance have been applied in previous studies by Gichuru et al. (2008) and Van der Vossen et al. (1976) where they were able to differentiate resistant and susceptible coffee arabica genotypes.

The genotypes containing the resistance gene were expected to show phenotypic resistance to CBD also banding patterns similar to the resistant coffee genotypes and resistance donors. The coffee genotypes lacking the resistance gene were expected to show phenotypic susceptibility to CBD and similar banding pattern to susceptible coffee variety KP423 (Gichimu et al., 2014). However coffee genotype 103 a hybrid between Rume Sudan and KP423, showed a band similar to KP423 (109) while phenotypically displayed resistance to CBD. This may be that Rume Sudan a resistance donor is having its resistance gene on different loci that could not match the marker Sat 235. This fact is supported by two works done separately by Kiguongo et al. (2014) and Omondi \& Pinard (2007) who located the resistance gene in Rume Sudan using SSR markers M24 and M24 and Sat227 respectively. Similarly, the Ethiopian coffee genotype F24/64/886 (110) displayed the pattern similar to the susceptible variety KP423 but phenotypically it displayed good resistance. This implied that its resistance gene was probably located in a different loci that could not match marker Sat235. Use of more markers in screening will lead to a more reliable results.

\section{CONCLUSION}

The presence of the coffee berry disease resistance genes was revealed in the studied coffee genotypes amplified by SSR marker Sat235 and Sat207. This was confirmed by production of bands similar to the progenitors of CBD resistance. This finding implied that marker screening can be used in coffee berry disease resistant genotypes selection at early stages of growth hence reducing the time of selection cycle.

\section{REFERENCES}

Diniz, L. E. C., Ruas, C. F., Carvalho, V. P., Torres, F. M., Ruas, E. A., Santos, M. O., Sera, T and Ruas, P. M. (2005). Genetic diversity among forty coffee varieties assessed by RAPD markers associated with restriction digestion. Brazil Archive Biology Technical 48(4): 511 - 521.

FAO (1968). Coffee Mission to Ethiopian 1964-1965. Food and Agriculture Organization, Rome, Italy. 200pp. 
Vol. 5, No. 03; 2020

ISSN: $2456-8643$

Fisher, R. A. (1958). Statistical Methods for Research Workers. (13 ${ }^{\text {th }}$ Ed.), Oliver and Boyd Edinburgh, London. 120pp.

Gichimu, B. M., Gichuru, E. K., Mamati, G. E and Nyende, A. B. (2014). Occurrence of Ck-1 gene conferring resistance to Coffee Berry Disease in Coffea arabica cv. Ruiru 11 and its parental genotypes. Journal of Agricultural and Crop Research 2(3): 51 - 61.

Gichuru, E. K., Agwanda, C. O., Combes, M. C., Mutitu, E. W., Ngugi, E. C. K., Bertrand, B. and Lashermes, P. (2008). Identification of molecular markers linked to a gene conferring resistance to coffee berry disease (Colletotrichum kahawae) in Coffea arabica. Plant Pathology 57(6): $1117-1124$.

Kiguongo, A. P. K., Omondi, C. O., Gichuru, E. K and Kasili, R. W. (2014). Analysis of simple sequence repeat markers linked to coffee berry disease resistance genes in a segregating population of arabica coffee (Coffea arabica L.). International Journal of Biotechnology and Food Science 2(8):156 - 166.

Omondi, C. O. and Pinard, F. (2007). Screening populations of Arabica coffee for molecular markers linked to Coffee Berry Disease resistance. $21^{\text {st }}$ International Conference on Coffee Science, held 11-15 ${ }^{\text {th }}$ September 2007, Montpellier, France. pp. $1377-1379$.

Poncet, V., Hamon, P., Minier, J., Carasco, C., Hamon, S. and Noirot, M. (2004). SSR crossamplification and variation within coffee trees (Coffea spp.). Genome, 47: 1071- 1081.

TCB (2012). Tanzania Coffee Industry Development Strategy 2011/2021. Tanzania Coffee Board, Moshi, Tanzania. 64pp.

Van der Graaff, N. A. (1978). Selection for resistance to coffee berry disease in arabica coffee in Ethiopia. Evaluation of selection methods. Netherlands Journal of Plant Pathology, 84(6): 205 215.

Van der Vossen, H. A. M. and Walyaro, D. J. (2009). Additional evidence for oligogenic inheritance of durable host resistance to coffee berry disease (Colletotrichum kahawae) in arabica coffee (Coffea arabica L.). Euphytica, 165(1): 105 - 111.

Van der Vossen, H. A. M., Cook, R. T. A. and Murakaru, G. N. W. (1976). Breeding for resistance to Coffee berry disease caused by Colletrotrichum coffeanum Noack (sensu Hindorf) in Coffea arabica L. I. Methods of preselection for resistance. Euphytica, 25: 733 - 745.

VSN International (2012). GenStat for Windows. (15 ${ }^{\text {th }}$ Edition). 